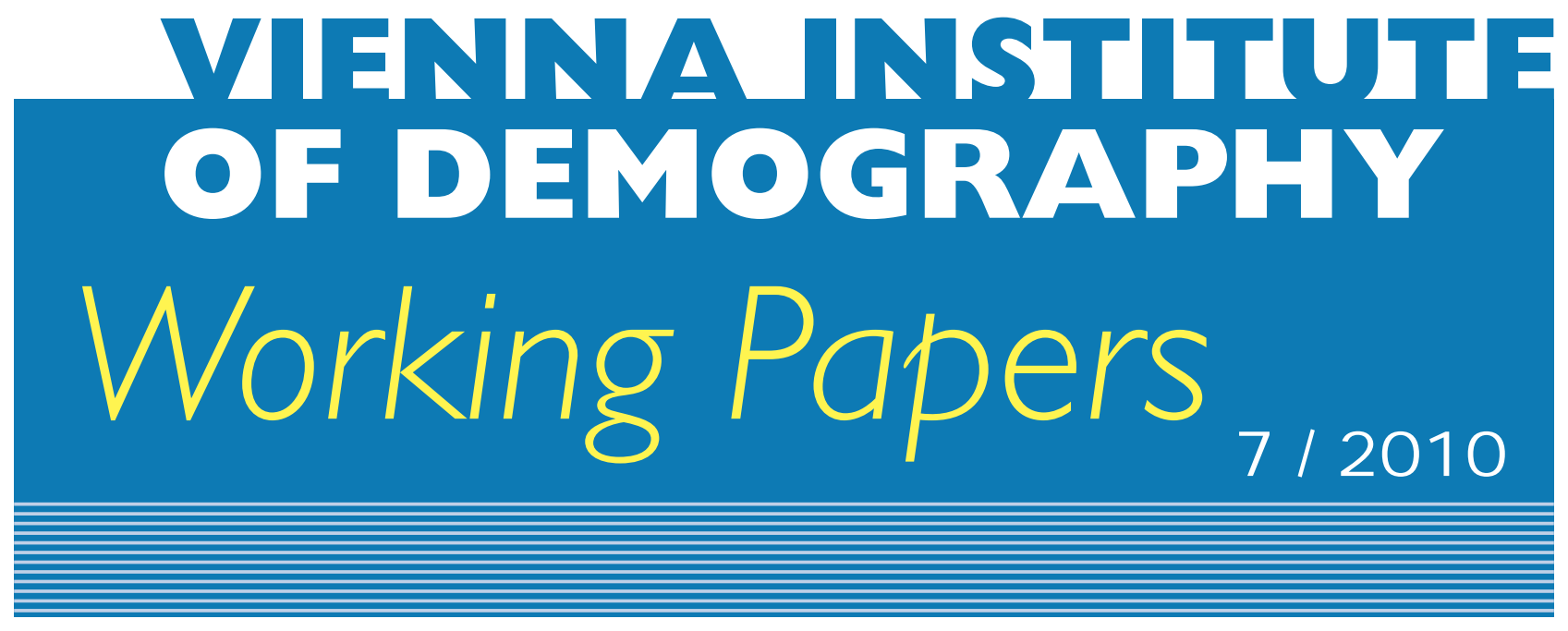

Priska Flandorfer, Christian W egner, and Isabella Buber

\title{
Gender Roles and Smoking Behaviour
}

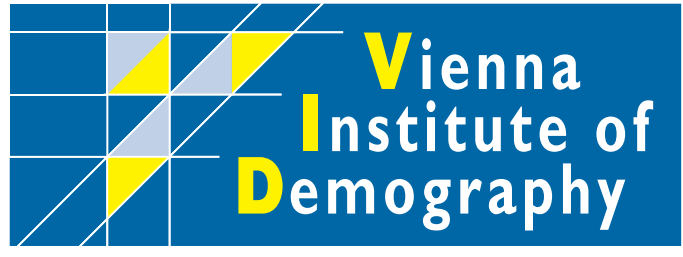

Vienna Institute of Demography Austrian Academy of Sciences

Wohllebengasse 12-14

A-I040Vienna $\cdot$ Austria

E-Mail:vid@oeaw.ac.at

Website: www.oeaw.ac.at/vid 


\begin{abstract}
The gender gap in smoking prevalence is closing in several developed countries due to decreasing smoking rates among men and increasing among women. Previous studies present a variety of hypotheses with the central argument that the process of gender equality is related to the declining trend regarding sex differences in smoking. We suppose that changes in traditional gender roles have influenced the smoking behaviour among both men and women. Our study focuses on the stereotypical masculine behaviour pattern which is assumed to be a smoking determinant and is increasingly adopted by females now. We applied a triangulation (combination) of qualitative and quantitative methods. The results indicate a connection between gender roles and health behaviour, especially smoking behaviour. The knowledge and experience of physicians reveal that although the attribute 'masculinity' is related to a higher risk of smoking it is increasingly adopted by women. The dynamic is further influenced by factors like age, social norms, workforce participation as well as mediaand leads to a change of perceived gender roles in society. This fact can partly explain the increasing amount of smoking women. From a methodological point of view the current study is an example for a successful triangulation of quantitative and qualitative methods. Precisely because both methods have different angles-the qualitative one focusing on the knowledge and experiences of physicians and the quantitative one on individual behaviour style-the results complement each other and yield a comprehensive picture.
\end{abstract}

\title{
Keywords
}

Triangulation, gender roles, smoking behaviour, gender gap.

\section{Authors}

Priska Flandorfer (corresponding author for qualitative part) is research scientist at the Vienna Institute of Demography of the Austrian Academy of Sciences. Email: priska.flandorfer@,oeaw.ac.at

Christian Wegner (corresponding author for quantitative part) is research scientist at the Vienna Institute of Demography of the Austrian Academy of Sciences. Email: christian.wegner@oeaw.ac.at

Isabella Buber is Research Scientist at the Vienna Institute of Demography of the Austrian Academy of Sciences. Email: isabella.buber@oeaw.ac.at

\section{Acknowledgements}

We thank Marc Luy, Katrin Fliegenschnee and the participants of the VID-colloquium for helpful comments and suggestions on an earlier draft. For language editing we want to thank Heike Barakat and Werner Richter. The work was conducted within the project 'The Gender Gap in Life Expectancy', funded by the Austrian Science Fund (FWF) (project P 20649 G14). 


\title{
Gender Roles and Smoking Behaviour
}

\author{
Priska Flandorfer, Christian Wegner, Isabella Buber
}

\section{Introduction}

Smoking prevalence is patterned by gender. In the early part of the 19th century tobacco consumption was largely restricted to males (Lopez, Collishaw \& Piha 1994; Ramström 1997; Waldron 1991b). The prevalence among men increased rapidly by the mid-20th century while the proportion of female smokers was still low. In the 1970s, men reached their highest level of smoking prevalence across most European countries. Indeed, the gender gap in cigarette consumption has narrowed because smoking among females has been spreading rapidly since the 1920s. Since 1970s the gap in smoking prevalence among women and men has continuously declined in European countries (Graham 1996; Pierce 1989). Males are supposed to still have the highest level of tobacco use but some recent studies present a higher smoking proportion among women, especially among younger age groups (Ali et al. 2009; USDHHS 2001).

Several hypotheses were presented to explain the gender differences in smoking behaviour. The most prominent ones refer to gender equality (Waldron 1991b) and to diffusion (Pampel 2001). On the one hand the lack in gender equality caused a later increase in female smoker prevalence by social disapproval of female smoking (Pampel 2001), on the other hand, the increase in gender equality due to the emancipation had tended to an adaptation of previously male smoking behaviour by females (Waldron 1991b). The increasing workforce participation of women is a major characteristic of gender equality. In this context, female smoking prevalence increased because 'employed women have been exposed more to the world of men's opinions and habits, employed women have been less subject to conventional constrains on women's behaviour, and employed women have had more access to money with which to buy cigarettes' (Waldron 1988, p. 196). Up to now, empirical analyses reveal inconsistent results for the association between smoking and workforce participation among females. Nevertheless, the idea that women have adopted men's opinions, habits and even behaviour as well as the opportunity to backslide from social perceived behaviour raises the following question: What is the association between gender role orientation and sex specific smoking prevalence?

Smoking as one of the most risky health behaviours is perceived to be a masculine phenomenon because of the related smoking pattern, personality traits and endorsement of hegemonic ideals. In comparison to females, men commence to smoke at younger ages, smoke more cigarettes per day, inhale more deeply and consume further tobacco products like pipes, cigars or smokeless tobacco (Haustein 2001; Waldron 1988). Personality traits like extroversion, rebelliousness, antisocial tendencies, risk taking and social deviance are directly related to the occurrence of smoking behaviour and are more frequent among males than females (Grunberg, Winders \& Wewers 1991; Waldron 1991a). The hegemonic ideals refer to men's health beliefs and behaviours which are the denial of weakness or vulnerability, emotional and physical control, the appearance of being strong and robust, the dismissal of any need for help, a ceaseless interest in sex and the display of aggressive 
behaviour and physical dominance (Courtenay 2000, pp. 1388-1389). This set of health beliefs and behaviours is often used by men to achieve and/or to demonstrate the perceived role of an independent, dominant, self-reliant and strong man. In this way, masculinity is defined by negative health behaviour due to adopting health risks like smoking, heavy drinking or not using or even avoiding health care (Garfield, Isacco \& Rogers 2008; Mahalik, Burns \& Syzdek 2007).

The question arises whether the described masculine characteristics also determine smoking behaviour among females. Has the emancipation led to adoption of traditionally male smoking behaviour by females because of social acceptance of female smoking or because of increasing female workforce participation? Numerous studies have used masculinity and femininity scores to empirically analyse gender differences. According to Emslie et al. (2002), high masculinity scores among men and women in non-manual jobs are associated with higher smoking risks, whereas femininity scores are not related to smoking. Indeed, Hunt et al. (2004) did not find any significant association between masculinity or femininity scores and smoking among men. But among women, smoking is associated with increasing femininity scores. Their analysis does not reveal consistent results but offers complex patterns in relation to gender roles and smoke behaviour.

Waldron (2000) suggests that the gender differences in health behaviour have been influenced by the interacting effects of fundamental aspects of traditional gender roles and the contemporary context. Her so-called 'gender roles modernization hypothesis' reevaluates the relation between gender roles and health behaviour in the way that females had evolved an own smoking style which evolved from traditional femininity roles and an increase in social acceptance of female smoking. It is - for example-well documented that body weight control is a main reason for smoking among women (USDHHS 2001). Women are more sensitive to their body constitution so that smoking might be an acceptable opportunity to keep their body weight down. Moreover, women are more likely to smoke in order to reduce stress (Brunswick \& Messeri 1984) which generally indicates high mental sensitivity.

The variety of hypotheses about sex differentials in smoking prevalence and the previous results indicate a complex but still inconsistent relationship between gender roles and smoking behaviour. Our analysis will extend the previous research by applying a triangulation of qualitative and quantitative methods to answer the following questions:

(1) Do gender roles determine sex-specific smoking behaviour?

(2) Does masculinity determine smoking behaviour among both males and females?

Our analyses can be embedded in the more broader context of mortality and the gender gap in mortality which is closing since the 1970s/1980s (Luy, Wegner \& Lutz 2010; Luy \& Zielonke 2009). The narrowing mortality sex differentials have been accompanied by a fall of the proportion of smokers among males and an increase in smokers among females (Lopez et al. 2006; Pampel 2002). Therefore, our study will reveal new insights in the relation between gender role orientation and sex differentials in smoking behaviour. 


\section{Method}

We applied a methodological triangulation of qualitative and quantitative methods for analysing determinants of sex differentials in smoking prevalence. In detail, we used an across-method triangulation (Begley 1996) to combine on the one hand experiences and knowledge of medical professionals about the smoking behaviour of their patients with representative data of individual smoking behaviour on the other hand. The triangulation of quantitative and qualitative methods is highly useful both for the research process and for the epistemological development of a research question. Both methods have different angles, the results complement each other and yield a comprehensive picture of the determinants of sex differentials in smoking prevalence (Flick 2006). The qualitative perspective is based on the methodology of the Grounded Theory strategy including theoretical sampling (Lamnek 1995) and constructing theories and concepts according to the coding paradigm (Corbin \& Strauss 1990). Sampling was based on theoretical considerations (theoretical sampling) throughout the entire project (Lamnek 1995).

Using expert interviews 20 general practitioners, five gender medicine researchers, two cardiologists and four geriatric nurses, who make a total of 31 participants, were interviewed in Austria in 2008 and 2009. The majority of them showed work experience of 20 years and more. The use of expert interviews is an appropriate qualitative method for the reconstruction of complex experiences and is used when the research interest has a focus on decision maxims, experiential knowledge, rules for action routines and knowledge relying on systematic problems, which can be mentioned explicitly or implicitly (Meuser \& Nagel 1997). It has to be mentioned that the current analysis is embedded in a study on gender differences in mortality. Therefore the expert interviews were designed rather broadly and were carried out in the context of behavioural factors and issues related to the health of men and women. It turned out that in various interviews different gender roles as well as smoking were mentioned by the interviewed experts in the framework of the gender gap in life expectancy.

While the qualitative analysis focused on behavioural sex differences and on the question which factors determine the sex differences in smoking behaviour, the quantitative analysis concentrates on the question how these factors influence the smoking behaviour of women and men. We used data of the western German first wave panel from the German Life Expectancy Survey (LES) of the German Federal Institute of Population Research (Gärtner 2001). The survey includes a representative population sample of 8,474 individuals born between 1914 and 1952 who were interviewed between 1984 and 1986 . Although the qualitative analysis focuses on experiences and quotations of Austrian medical professionals the results can be compared to and extended by German quantitative data as the trends in smoking prevalence, smoking attributable mortality and overall mortality have nearly the same pattern in Austria and Germany (Lopez et al. 2006; Luy, Wegner \& Lutz 2010).

The LES was first carried out in 1984/86 and hence includes characteristics of individuals from 30 years ago. It has to be mentioned that the results of the qualitative analysis are based on physicians' long-term experience of mostly older patients with health problems or former patients who have already died. Based on the life course approach 
(Kuh \& Ben-Shlomo 2004) both the morbidity or survival status of patients are influenced by the accumulation of health risks like smoking during the whole life span. The model of smoking epidemic (Ramström 1997) suggests a time lag of about 30 years between regular smoking and resulting morbidity and mortality status. Consequently, the use of the LES considers the time lag between risk behaviour and caused health status in an appropriate perspective.

The triangulation process followed a circular shape. We briefly describe the method of triangulating (combining) data following how this was implemented in our own research. The results that emerged either during the qualitative or the quantitative analysis guided the overall research process and were complemented with results of the other method. A literature review and first findings of a short preliminary quantitative analysis were incorporated in the construction of the interview guideline. As common practice in Grounded Theory, we started without any hypotheses at the beginning of the interview phase. Since we worked with specific research questions which guided the sampling and the data collection, it was possible to reveal categories and hypotheses during the circular analysis process. The coding process of the first interviews resulted in first categories and concepts. According to these first results the research questions may be refined and actually were refined in the current study. The method of theoretical sampling offered the possibility to broaden the sample and to ask persons who can contribute to answer the research questions from another point of view. Following this strategy, the sample of the interview participants and the guideline of the interviews were adapted several times. After finding the core category, the theoretical model based on the data was developed and results were formulated. These results were discussed and related to previous findings in the literature. The search for appropriate data is crucial for a triangulation since it is necessary to find quantitative data that include the relevant information and items. To our knowledge, the German LES was the only available dataset appropriate to this purpose. In general, the first hypotheses may be supported or rejected and-either way-the analysis then turns again to the qualitative approach where the rejected or supported hypotheses guide the next steps of the overall research process.

\section{Qualitative Model}

The results of the qualitative research are based on the perception of the interview participants about gender roles. The observations and the experience of our interviewed experts yielded an association between perceived gender roles and smoking behaviour. Therefore, our model was called 'perceived gender roles'. It is grounded in the analysis of the data we collected during the interview phase and consists of three main categories, called attributes, influence factors and generation change (Figure 1). These three categories are discussed in relation to gender specific smoking behaviour patterns. 
Figure 1: Model of perceived gender roles

\section{Perceived Gender Roles}

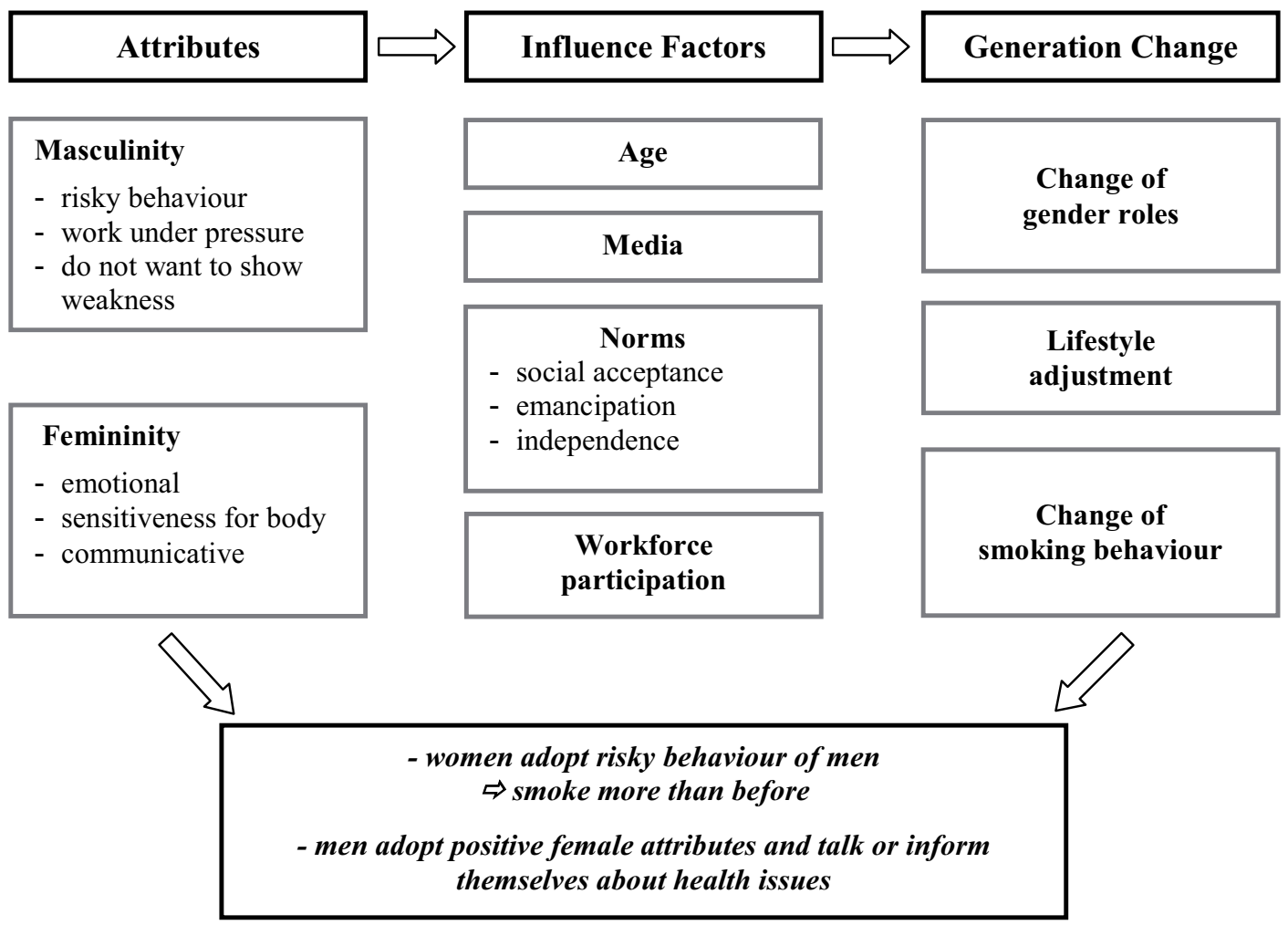

Source: own research results

The theoretical model 'perceived gender roles' is based on the Grounded Theory analysis of the expert interviews and emerged through the data. The first category 'attributes' subsumes masculinity and femininity aspects, mainly in connection with health behaviour in general and smoking behaviour in detail. The next category 'influence factors' describes which factors lead to a change of gender roles according to health behaviour. These factors are age, the media, norms and the workforce participation. It was perceived that women at younger ages smoke more than women at older ages. These changing female smoking behaviour patterns can be explained by specific changing norms in our society. Nowadays it is socially accepted that women smoke. This reflects the emancipation and independence of women. Women are independent of men because they have higher workforce participation than before. The media are another influence factor in regard to the changing smoking behaviour patterns. Information about health is spread through various channels and this is mainly positive for men. Today, they tend to inform themselves more about health issues and it is also more common to know that smoking leads to perilous diseases. Even though women inform themselves via media, their 
masculinity influence factors regarding smoking behaviour are considered to be very strong. Therefore, this generation change, which is the third category, leads to a change of gender roles in general and as a consequence to a change of smoking behaviour where women adopt risky behaviours of men and men are considered to be more health conscious. We continue with several quotations of experts in order to illustrate our theoretical model of 'perceived gender roles'.

\section{$\underline{\text { Attributes }}$}

The categories 'femininity' and 'masculinity' reflect the fact that men and women are seen as still acting rather traditionally. For example, one attribute that was connected with male patients was the fact that men try to behave in a dominant way.

...there's still this old myth of the hero, and so the ruinous lifestyle is considered as a male thing, also in their own self-perception. (General practitioner)

To be a hero and to live without considering risks and not to take care of one's health was connected with the image of being a 'real man'. Several interview partners referred to this phenomenon. Consequently, men were perceived to live a more dangerous life because this was associated with the understanding of their gender. Especially tobacco and alcohol use were related to men. This behaviour was still connected with the idea of 'real men'. The following quotation explains masculinity with regard to risky behaviour.

'Cause it's a male thing. 'Cause it's a male thing to smoke and to drink and to hang around in the bars and to thump the table. And 'cause a fat belly doesn't have that bad an image than for women. (General practitioner)

To be strong and to be able to work under pressure was another thing that was seen as rather masculine.

[They] take off like an arrow, like the real macho thing, right off. Full speed, ready to take on anything at full throttle, wham-blam, and then suddenly they lose their breath and fall flat on their face... (General practitioner)

The opposite of this perceived behaviour was connected with emotions and femininity. Women were described as being rather emotional in a very positive way. Their sensitiveness for their body and their feelings were described as healthy.

Women have more access to their emotionality. And so they probably tend to reflect more and just do more for their own mental hygiene. For a man, it is not very chic to talk about feelings. (General practitioner)

Because women tend to listen more to their own body they realise much earlier if something becomes different. The first step is realising that things are wrong, which is the precondition for beginning to change something about it. 
Regarding smoking there also existed perceivable masculinity and femininity patterns. Smoking is an addiction with various gender specific aspects.

As for smoking, I'm sure one can find many things about it in gender studies: first of all, the use of cigarettes as stress-busters, this coping strategy is much more pronounced among women, in this psychosocial context, than it is among men. Men are much more, to a greater extent, nicotine-addicted, while the psychosocial dependence is more dominant for women, and only a minority of them is really addicted to nicotine as a substance. When looking at relapse frequencies it is easy to see that for men these are above all situations which have a positive connotation to them, and for women this is much more due to stress and conflicts ... And this shows that risk factors cannot simply be assigned and counted and evaluated, but that there is always a particular behaviour behind them that acts as a pattern.

(Gender medicine researcher)

This quotation shows very well that smoking behaviours of men and women are different. Whereas men have a higher prevalence of being addicted to nicotine, women are addicted mainly because of psychosocial factors. Stress is a main element of the smoking addiction and with this respect women seem to use smoking as a coping strategy.

\section{Influence Factors}

The interviewed physicians were aware of the fact that the changing smoking behaviour is related to age. Especially women start to smoke at younger ages nowadays and smoke more cigarettes compared to older cohorts. A change of various factors in society has led to more risky behaviour and women seem to adopt this from men.

I think it is a general fact that the younger population is certainly more overweight, has more stress and higher blood pressure, and smokes more, than one has ever seen for the older population. (General practitioner)

Physicians, cardiologists and gender medicine researchers perceived that young women nowadays tend to smoke more often than young men.

The media are another influence factor because they also inform about health issues. Information about smoking is crucial for a better understanding of the underlying risk factors that can evolve as a consequence of this addiction. The information provided by the media were regarded to have a positive impact on men in the sense that they get better informed about the risk factors of smoking and tend to try to quit smoking. One consequence of the observation that health debates are becoming more and more topical is that individuals are more likely to talk about their health problems within their personal social networks. The media are one more reason why it is more common today, even for men, to exchange health issues in their peer groups.

Maybe because the information campaigns about health screening tests and healthy lifestyles have finally arrived in the male consciousness, and so it's probably a generation thing that men now do care some more about their health. (General practitioner) 
It was also argued that this generational shift was in fact due to educational campaigns promoting health checkups. Due to information and peer-group exchange men nowadays concentrate more on their health than the generations before. For women the information spread by the media do not have these strong effects, according to the experience and observations of the interviewed experts.

Other influence factors regarding the change of gender roles are the changing norms in our society. Nowadays, smoking women are more socially accepted.

I think that it's simply like that in society, like in the past a smoking woman was simply much less tolerated, and today this isn't a problem anymore - I mean nobody disapproves of a woman just because she smokes, nobody will mind today. (General practitioner)

Changing sex role norms have led to an adoption of smoking by women. Since it has become accepted for women to smoke, smoking was also seen as a part of an emancipation process of women. Today, they have the right to be part of spheres that were formerly mostly related to men. And women have adopted male behaviour also with regard to smoking.

The young women want to see themselves more emancipated. And they simply want to prove that and [adopt] those bad habits-smoking and drinking - and this is the wrong kind of emancipation. (Gender medicine researcher and cardiologist)

This emancipation process therefore leads not only to the liberation and independence of women. Since women can also be the breadwinners of the family, nowadays, or have to care for their children as single mothers, they have more duties, and this leads to more stress. They want to cope with this stress and, as mentioned before, one of the coping strategies is the use of cigarettes.

Due to emancipation, the women partly step into the role of the man. There are many families today where the woman simply earns more than the man and therefore she also takes up this responsibility for the family. As a consequence, she is practically faced with all this social stress, and she is also more challenged to act that role, and this certainly leaves its traces. (General practitioner)

This leads to a next influence factor which is the workforce participation. Nowadays, women are more active on the employment market than decades before. The way this was seen, in relation to the increasing smoking addiction of women, is demonstrated by the next quotation.

I think it has to do with very many women having adopted a masculine life style. This means that the role a woman in certain positions is actually only approved through her accepting or adopting a masculine life style. Think of a female executive: she eventually takes up a very male life style, not only in her language and activities but also in her way of dressing. And I think that these in a way additional stress factors also [explain], for instance, the increased female nicotine consumption. (Gender medicine researcher and cardiologist)

What emerged from the qualitative data was also the hypothesis that power and strength are related to masculine behaviour. Consequently, masculine behaviour is related 
to being risky and ruinous. To be successful at work, especially in higher positions, is related to power and high engagement which often leads to stressful situations that stimulate risky behaviour. Men show more over-commitment to their profession and are more competitive. Decades ago, women tended to be more active in the household and had lower workforce participation. Since gender roles have changed due to changing norms, transformation of the family and the employment system, women participate more in public spheres. This leads to the next category of our model, namely, the generation change.

\section{Generation Change}

As mentioned before, gender roles have changed and a lifestyle adjustment of men and women was observed by the interviewed experts. Especially women adopt a masculine lifestyle, and this was highly linked to their increased workforce participation. The next quotation precisely shows this lifestyle adjustment with regard to women.

Women used to lead quite different lives in comparison to today, and today we notice that when women smoke, when women work and women have the dual burden of paid work and child care, then female mortality is more and more approaching that of men.

(General practitioner)

This lifestyle adjustment has led to a change of smoking behaviour as well. As women adopt a male lifestyle they smoke more than before. They show higher competitiveness, higher commitment to their profession and are more engaged in higher positions. All these perceived behaviour factors were mentioned according to smoking which leads to the following trends.

The negative aspects are converging since women don't want to be women any more, they actually want to be like men, as this is the cliche of success, it's the man. The successful woman is in fact a woman who has taken up male behaviours.

(Gender medicine researcher and cardiologist)

Success was considered to be masculine. If women want to exist and be successful in male territories the best way seems to adopt masculine behaviour. So the changing gender roles could be seen as a lifestyle adjustment of women towards male behaviour which might point to the trend that traditional gender roles assimilate or dissolve.

Men have also adopted attitudes that were ascribed to women, but not as much as women adopt male attributes. Especially there has been a change in the health behaviour of younger men in relation to older men. The practitioners explained this phenomenon with a new 'type of men':

And then there [is] this rather new phenomenon, they are at least just as exhausting, I mean the ones from fifteen [years] to their mid-thirties - an entirely new type of men.

(General practitioner) 
This new 'type of man' has a much deeper relation to his body. He is informed about various health products, and with regard to this new type of man, health gets more relevant in the media. As a consequence men go to health prevention checkups more often. In comparison to the patriarchal kind of men in their forties and fifties, these men are more health-conscious now:

So, well, this old-school type in the, I don't know, the 1940s or 1950s or thereabouts, these blokes weren't even interested in their health. (General practitioner)

Regarding male health behaviour it is obvious that there has been a generational change. Younger cohorts are now giving broader consideration to health-related issues. As described men seem to adopt female attributes which has positive effects on their health behaviour. On the contrary, women adopt negative male attributes especially in connection with workforce participation. Since power, competitiveness, over-commitment and engagement are elements of successful work participation and since these factors are proven to trigger risky behaviour like smoking, women also adopt them regardless of their negative aspects. What makes the situation even worse is the fact that after the birth of a child, women are often primarily responsible for household tasks and childrearing duties and the division of household work becomes very traditional, even if it was equally shared by both partners before the birth of the child. Women often do not want to give up their successful work participation once they have a child. But after giving birth they tend to relapse again into the traditional female role where they have to be the main caregiver of the children. For mothers who want to return to the labour market and remain successfully employed, the reconciliation of family and employment is often difficult and implies stress. Some of them compensate their stressful situation with unhealthy behaviours like smoking.

The qualitative model is based on experience and knowledge of general practitioners, geriatric nurses, cardiologists and gender medicine researchers. They might have had different professional backgrounds but interestingly their perception of men's and women's behaviour was quite the same when it came to health behaviour and smoking. Only their approach towards their clients was different. Physicians did see them more from a medical perspective and had long-term experiences with their patients whereas gender medicine researchers referred also to their scientific knowledge about differences in male and female behaviour patterns. Geriatric nurses could contribute to the research by referring to their experience with the care of older clients. The fact that these groups saw their patients or clients from different perspectives was not a problem during the analysis process. On the contrary, it was-according to the principles of the theoretical samplingvery fruitful and their views yielded a broader in-depth picture of the phenomenon.

Our results of the qualitative analysis can be summarised as follows: Smoking is related to the concept of gender roles. Gender roles are changing which has effects on the overall health behaviour of men and women. Because of changing norms and higher workforce participation, women have adopted masculine behaviours including smoking behaviour, whereas men have adopted positive female health attributes. The media promotes health issues more than before which has a positive influence on men but a neutral influence on women. The main conclusion implies that smoking is related to gender roles and to the shifting social norms and responsibilities of men and women. 


\section{Quantitative Model}

The qualitative analysis revealed that gender roles in general and changes in traditional gender role behaviour patterns in particular are associated with health behaviour, especially with smoking. Following the principles of a methodological triangulation, our quantitative analysis therefore focused on the relation between gender roles and smoking behaviour. It has to be underlined that it is not the purpose of a triangulation to test the results of the qualitative analysis but to find further associations between gender roles and smoking in quantitative data. In this way, our qualitative and quantitative analyses are seen as equivalent methods which yield a comprehensive picture of the relation between gender roles and smoking. A further methodological argument is the fact that our triangulation combines observations of medical experts with self-reported smoking behaviour of persons aged 30 to 69 years. These different views were well reconcilable.

The quantitative analyses focus on the association between gender role orientation and smoking behaviour controlling for socio-demographic determinants. We measured the gender role orientation by the Bortner Type A personality scale. This measure refers to an individual's personality which is indirectly formed by the impact of gender roles on the processes of socialization and social interaction (Sieverding 2005). In fact, the so-called Type A is 'a style of personality characterised by some or all of the following attributes: intensive striving for achievement; competitiveness; easily provoked impatience; time urgency; abruptness of gesture and speech; over commitment to vocation or profession; excesses of drive and hostility' (Jenkins 1976). Blascovich et al. (1981) suggested that Type A personality may correlate with smoking, too. The counterpart of Type A personality is Type B which is characterised by the relative absence of Type A patterns. DeGregorio and Carver (1980) as well as Blascovich et al. (1981) have analysed that both males and females of Type A scored higher on the 'Masculinity' subscale of the Bem Sex Role Inventory scale (Bem 1974) than those of Type B. Furthermore, it is assumed that the Type A personality style is a result of social reinforcement for engaging traditionally masculine activities (Waldron 1978). Indeed, recent research has not explored any association between Type A personality and femininity (Harrison 1978).

The LES contains all 14 questions of the Bortner Type A scale. The resulting scale was classified into three groups. The first category 'Extreme Type A personality' includes all persons with extreme Type A scores whereas 'Extreme Type B personality' contains all individuals with extreme Type B scores. The last category 'Type AB' summarises all persons with moderate Type A or Type B personality.

The individual smoking behaviour is characterised by a variety of indicators in the LES like smoking status, number of cigarettes per day, initial age at smoking and in case of former smokers the age of smoke cessation. We choose a dichotomised variable indicating the current smoking status. Further information included in the LES is used, namely age, education, current employment status and marital status. Recent research pointed out that those indicators were related to smoking behaviour. Furthermore, the qualitative results indicate age and employment status as important characteristics of the category 'influence factors' which are related to higher risk of smoking. Age was classified into four 10-years 
age groups involving the range from age 30 to 69 . The level of education was measured by means of the international standard classification of education ISCED-97 (OECD 1999). The corresponding categories are 'primary', 'secondary' and 'high' education. Several studies explored an education gradient relating to smoking prevalence (Helmert, Borgers \& Bamman 2001; Stellman \& Resnicow 1997; Wagenknecht et al. 1990). The prevalence is lower among high educated than among low educated persons. The current employment status distinguishes between individuals who are currently employed and those who are non-employed. In fact, the non-employed persons except age group 60-69 are mainly housewives. The empirical evidence of the relation between workforce participation and higher rates of smoking is less consistent for females (Waldron 1991a). But recent studies indicated that Type A personality is positively related to working women and men (Haynes $\&$ Feinleib 1980). The marital status contains three categories 'married', 'ever married' (summarising divorced and widowed individuals) and 'non-married'.

Table 2: Basic descriptive characteristics of sample in \%

\begin{tabular}{|c|c|c|c|c|c|c|c|c|c|}
\hline & \multirow[t]{2}{*}{ Age Group } & \multicolumn{2}{|c|}{ 30-39 } & \multicolumn{2}{|c|}{ 40-49 } & \multicolumn{2}{|c|}{$50-59$} & \multicolumn{2}{|c|}{$60-69$} \\
\hline & & Women & Men & Women & Men & Women & Men & Women & Men \\
\hline \multirow{2}{*}{$\begin{array}{l}\text { Smoking } \\
\text { status }\end{array}$} & Current smoker & 37.0 & 46.8 & 23.6 & 42.0 & 13.6 & 38.0 & 13.9 & 32.8 \\
\hline & Never smoker & 41.6 & 25.6 & 59.1 & 26.9 & 72.6 & 23.3 & 69.9 & 15.3 \\
\hline \multirow{3}{*}{$\begin{array}{l}\text { Bortner type } \\
\text { A scale }\end{array}$} & Extreme Type A & 19.4 & 22.6 & 17.9 & 23.4 & 13.9 & 18.3 & 7.8 & 9.4 \\
\hline & Extreme Type B & 11.9 & 13.1 & 13.0 & 12.2 & 21.7 & 18.8 & 35.0 & 29.6 \\
\hline & Type AB & 68.7 & 64.3 & 69.0 & 64.4 & 64.5 & 62.9 & 57.2 & 61.0 \\
\hline \multirow[t]{3}{*}{ Education } & Highly educated & 21.9 & 41.6 & 11.9 & 33.2 & 8.3 & 27.9 & 8.1 & 26.8 \\
\hline & Middle educated & 61.3 & 54.0 & 58.8 & 58.5 & 47.4 & 61.1 & 52.1 & 63.6 \\
\hline & Primarily educated & 16.8 & 4.4 & 29.3 & 8.3 & 44.4 & 11.0 & 39.8 & 9.6 \\
\hline \multirow{2}{*}{$\begin{array}{l}\text { Employment } \\
\text { status }\end{array}$} & Employed & 62.7 & 98.5 & 62.4 & 97.9 & 50.2 & 91.1 & 9.5 & 24.5 \\
\hline & Non-employed & 37.3 & 1.5 & 37.6 & 2.1 & 49.8 & 8.9 & 90.5 & 75.5 \\
\hline \multirow{3}{*}{$\begin{array}{l}\text { Marital } \\
\text { Status }\end{array}$} & Married & 87.0 & 81.0 & 85.3 & 86.8 & 79.4 & 90.8 & 60.1 & 89.8 \\
\hline & Ever married & 7.4 & 3.7 & 8.9 & 5.6 & 14.0 & 4.9 & 31.3 & 6.9 \\
\hline & Never married & 5.8 & 15.3 & 5.8 & 7.6 & 6.6 & 4.3 & 8.6 & 3.2 \\
\hline Total n & & 808 & 810 & 1121 & 1349 & 895 & 1072 & 591 & 649 \\
\hline
\end{tabular}

Source: German Life Expectancy Survey

Table 2 presents the descriptive details of the sample. The prevalence of current smokers is highest among young cohorts and decreases with age which is consistent with previous findings in the literature. Nearly four out of ten women and one out of two men aged 30 to 39 years declared to consume more or less regularly tobacco, whereas only $14 \%$ of women and one third of men aged 60 to 69 did so. In all age groups, more men than women were current smokers. Especially beyond the age of 50 years rather few women light a cigarette (14\%), whereas their male contemporaries declared themselves more often as smokers (50-59: 33\%; 60-69: 33\%). 
LES allows to identify persons who have never smoked. In our multivariate analysis we concentrated on current smokers, as opposed to non-smokers. The reason therefore is the fact that ever smokers-as opposed to never smokers - are a rather inhomogeneous group which includes current and former smokers. This requires a sophisticated modelling which takes into consideration the tobacco abstinent time span of former smokers, which is beyond the scope of this paper. Whereas the proportion of never smokers is increasing substantially with age among women, it is decreasing among men: For women, $42 \%$ of younger cohorts but $70 \%$ of older cohorts have never smoked a cigarette on a regular basis. Among men, the proportion of never smokers is quite stable around roughly $25 \%$ for age groups 30 to 59 years, and decreases to $15 \%$ for the age group 60 to 69 . Our descriptive statistics clearly reflect cohort effects for men and women which are in line with findings on smoking prevalences of both sexes.

With regard to the indicators for gender role orientation we find that the extreme Type A personality declines with older age, varying between $23 \%$ for males at age group 40 to 49 and $8 \%$ among women of the age group $60-69$. The sex difference is around 4 per cent points between ages 30 to 59 and very small ( 2 per cent points) for the oldest age group. The proportion of the extreme Type B decreases with age for both sexes to $35 \%$ among women and 30\% among men. Among all age groups, type A is more frequent among men compared to women. Turning to the characteristics we controlled for we find that men are higher educated than females in all considered cohorts. As expected, younger cohorts more often completed tertiary education than older cohorts, which is especially the case for women. The proportion of currently employed males is above $90 \%$ until the age of 59 and decreases to $25 \%$ for the oldest age group. In Germany the official age for retirement is 65 years for men and 60 years for women. Our descriptive results reflect the transition to retirement in the age group 60 and above. ${ }^{1}$ It has to be mentioned that our data were collected in western Germany between 1984 and 1986 and therefore reflect the labour market situation at this period, and cannot be compared with current employment rates. Among females, the level of employment is substantially lower and around $62 \%$ up to the age of 49 , decreasing to $50 \%$ for women in their fifties and $10 \%$ to women in their sixties. Again, our data give evidence of the increasing labour force participation of younger cohorts and the earlier transition to retirement compared to men. Living with a spouse is the dominant marital status, the proportion of 'married' is above $80 \%$ for men throughout all age groups. As expected, the proportion of 'married' declines with higher ages among women because of higher mortality risk among men as well as gender specific age differences in couples. Until the age of 50, 'divorced' constitutes the majority of 'ever married', whereas at higher age groups, widowhood is the main reason for belonging to this category. Women are more often affected by widowhood compared to men.

\footnotetext{
${ }^{1}$ In 1985 , the mean retirement age was 60.4 years for men and 58.7 years for women Verband Deutscher Rentenversicherer 2009, Rentenversicherung in Zeitreihen, Berlin.
} 
Table 3: Estimated odds ratios of current smokers among females by age group

\begin{tabular}{|c|c|c|c|c|c|c|c|c|c|}
\hline & & \multicolumn{2}{|c|}{ 30-39 } & \multicolumn{2}{|c|}{$40-49$} & \multicolumn{2}{|c|}{$50-59$} & \multicolumn{2}{|c|}{$60-69$} \\
\hline & & OR & Sig. & OR & Sig. & OR & Sig. & OR & Sig. \\
\hline \multirow{3}{*}{$\begin{array}{l}\text { Bortner type } \\
\text { A scale }\end{array}$} & Type AB & 1.00 & & 1.00 & & 1.00 & & 1.00 & \\
\hline & Extreme Type A & 1.03 & & 1.87 & $* * *$ & 1.38 & & 0.54 & \\
\hline & Extreme Type B & 0.86 & & 1.13 & & 1.39 & & 1.14 & \\
\hline \multirow[t]{3}{*}{ Education } & Highly educated & 1.00 & & 1.00 & & 1.00 & & 1.00 & \\
\hline & Middle educated & 2.30 & $* * *$ & 1.84 & $*$ & 1.02 & & 0.76 & \\
\hline & Primarily educated & 3.27 & $* * *$ & 1.56 & & 0.69 & & 0.50 & \\
\hline \multirow{2}{*}{$\begin{array}{l}\text { Employment } \\
\text { status }\end{array}$} & Employed & 1.00 & & 1.00 & & 1.00 & & 1.00 & \\
\hline & Non-employed & 0.63 & $* *$ & 0.60 & $* *$ & 0.76 & & 0.47 & * \\
\hline \multirow{3}{*}{$\begin{array}{l}\text { Marital } \\
\text { Status }\end{array}$} & Married & 1.00 & & 1.00 & & 1.00 & & 1.00 & \\
\hline & Ever married & 2.24 & $* *$ & 2.23 & $* * *$ & 1.88 & $*$ & 2.18 & $* *$ \\
\hline & Never married & 3.76 & $* * *$ & 1.37 & & 1.27 & & 0.55 & \\
\hline \multicolumn{2}{|l|}{ McFadden $\mathbf{R}^{2}$} & 0.58 & & 0.54 & & 0.32 & & 0.44 & \\
\hline \multicolumn{2}{|l|}{$\mathbf{n}$} & 808 & & 1121 & & 895 & & 591 & \\
\hline
\end{tabular}

$\dagger \mathrm{p}<0.1, * \mathrm{p}<0.05, * * \mathrm{p}<0.01, * * * \mathrm{p}<0.001$

Source: German Life Expectancy Survey

Table 4: Estimated odds ratios of current smokers among males by age group

\begin{tabular}{|c|c|c|c|c|c|c|c|c|c|}
\hline & & \multicolumn{2}{|l|}{ 30-39 } & \multicolumn{2}{|l|}{$40-49$} & \multicolumn{2}{|c|}{$50-59$} & \multicolumn{2}{|c|}{$60-69$} \\
\hline & & OR & Sig. & OR & Sig. & OR & Sig. & OR & Sig. \\
\hline \multirow{3}{*}{$\begin{array}{l}\text { Bortner type } \\
\text { A scale }\end{array}$} & Type AB & 1.00 & & 1.00 & & 1.00 & & 1.00 & \\
\hline & Extreme Type A & 1.10 & & 1.18 & & 1.15 & & 1.12 & \\
\hline & Extreme Type B & 1.50 & $\dagger$ & 1.27 & & 1.50 & * & 1.64 & ** \\
\hline \multirow[t]{3}{*}{ Education } & Highly educated & 1.00 & & 1.00 & & 1.00 & & 1.00 & \\
\hline & Middle educated & 1.40 & * & 1.36 & $*$ & 1.38 & $*$ & 1.20 & \\
\hline & Primarily educated & 1.74 & & 2.12 & $* * *$ & 1.82 & $* *$ & 1.12 & \\
\hline \multirow{2}{*}{$\begin{array}{l}\text { Employment } \\
\text { status }\end{array}$} & Employed & 1.00 & & 1.00 & & 1.00 & & 1.00 & \\
\hline & Non-employed & 2.00 & & 1.42 & & 1.14 & & 0.64 & * \\
\hline \multirow{3}{*}{$\begin{array}{l}\text { Marital } \\
\text { Status }\end{array}$} & Married & 1.00 & & 1.00 & & 1.00 & & 1.00 & \\
\hline & Ever married & 2.95 & ** & 1.86 & $*$ & 1.37 & & 1.01 & \\
\hline & Never married & 1.40 & $\dagger$ & 1.77 & $* *$ & 1.16 & & 1.21 & \\
\hline${\text { McFadden } \mathrm{R}^{2}}^{2}$ & & 0.49 & & 0.53 & & 0.34 & & 0.23 & \\
\hline $\mathbf{n}$ & & 810 & & 1349 & & 1072 & & 649 & \\
\hline
\end{tabular}

Source: German Life Expectancy Survey 
The second step of the quantitative analysis includes a multivariate analysis of the relation between current smoking status and Type A personality controlled for educational degree, employment and marital status. Both for men and women, we estimated by standard logistic regressions odds ratios of being current smoker for all age groups separately.

Table 3 presents the estimated odds ratios for current smokers among women and Table 4 for men. Extreme Type A personality as an indirect measure of masculinity was significantly related to smoking only among women aged 40 to 49. Extreme Type B personality was notably associated with current smoking among men aged 50 to 69 . The estimated coefficients for the remaining age groups did not reveal a statistically significant association between personality and current smoking status. Indeed, there are strong relations between middle and primary education and current smoking among men aged 40 to 59 and among females at younger age groups (30-49). Currently employed persons are more likely to smoke than non-employed. In detail, housewives as well as male pensioners have significantly lower odds for smoking. Regarding marital status, ever married is related to current smoking among women at all age groups and among men at ages 30 to 49. The models accounted for $32-58 \%$ of variation in the outcome measure among females and $23-53 \%$ among males.

\section{Discussion}

The triangulation of qualitative and quantitative methods as we used it in this paper has proved to be highly fruitful because it provided us with versatile results. Not only to look at a phenomenon through different methodological angles but also to complement and broaden the results with methods associated with the two research paradigms was the main advantage of this research. This strategy offered us the possibility to follow a circular research process where we flexibly formed and revised our research questions as well as the sampling and the interview guideline according to the development of new hypotheses. Not being stuck in one methodology we could overcome the weakness of one method with the other method. But there are some points which had to be considered and dealt with. As already mentioned, the participants of the qualitative analysis have different professional backgrounds and therefore different approaches to interpret or explain differences in health behaviours of their patients. The mixture of experiences could bias the overall perspective but it contains a lot of information that cannot be collected only through quantitative analyses. Furthermore, the perception of men's and women's health behaviour was quite the same among different professions. It can be questioned why experts were asked about the health behaviour of men and women and not individuals themselves. But exactly this proved to be very positive because the experts had a long term perspective about the health behaviour of their male and female clients and their view was objective because their observations resulted from a holistic perspective. A limitation seemed to be the crosssectional structure of the data. We could not analyse changes in the smoking behaviour and the related determinants. Although the cohort specific perspective presents robust results the analysis could be biased by period effects. We quantified indirectly the gender role orientation by the Bortner Type A personality scale. This scale does not frame the full concept of gender roles but presents a part of masculinity related to gender roles. Other measures like Bem Sex Role Inventory or Personal Attributes Questionnaire (Spence \& 
Helmreich 1978) were not available in representative Austrian or German surveys. But to make it clear, limitations only existed with regard to data restrictions but not to methodological issues. This leads us to the suggestion of adding scales for identifying gender roles to national surveys because our research results indicated that these scales are important for the understanding of individual health behaviours with regard to gender roles and sex differences in health behaviour.

Considering the effectiveness of triangulation as a method there are two points mentioned in previous research: confirmation and completeness of data (Begley 1996). Combining qualitative and quantitative data, Jick (1979) came to quite the same conclusion when producing largely consistent and convergent results but the different methods also led to dissimilar results. By concentrating on explaining those inconsistent results he mentioned that this raised the opportunity for enriching the explanation. With regard to the use of triangulation of methods in our research we want to point out that confirmation or consistent results seemed not to be the most important goals for a multi-method study. In fact it turned out that the different angles made it possible to enrich the analysis by - for example - broadening the qualitative sample, refining the interview guideline or searching for other control variables for the statistical analysis.

To sum up we want to emphasise one important point in this triangulation research: the purpose was not to primarily validate the results each method provided, but to give a broader picture of the phenomenon by mixing those two methodologies. Denzin stated that the goal of 'triangulation is a fully grounded interpretive research approach' where 'objective reality will never be captured' and where an 'in-depth understanding, not validity', should be sought (Denzin 1989, p. 246). In fact, this prerequisite turned out to be met - our results are manifold and offer a rich background not only for further thematic research but also for the epistemological development of the triangulation as a promising research approach. The results of the triangulation offer a variety of interpretable impacts on smoking behaviour influenced by gender roles. With regard to social norms and smoking our results support the gender equality hypothesis of Waldron (Waldron 1988, 1991b). Gender equality has led to a change in smoking behaviour of men and women. Social acceptance of smoking women caused a later increase in female smoking prevalence. The former social disapproval of women's smoking was accompanied by perceptions of traditional sex roles. Men were considered to have more social power than women and there were more restrictions on women's behaviour than on men's behaviour also with regard to the social acceptance of smoking. Women's social status has improved over the last decades and the restrictions concerning their behaviour diminished which resulted in an increasing similarity of male and female roles (Waldron 1991b). Our results present a decline in never smoker proportion among females. The proportion drops to $30 \%$ among women born after 1935 in comparison to older women. Beside, the differences in the proportion of current smokers among female cohorts increased much stronger than among males. Both characteristics indicate that women born after 1935 adopted smoking as a life course experience because of the emancipation process during the 1960's and1970's.

Our qualitative results, especially supported by the empirical category 'generation change', show in fact strong evidence that traditional gender roles are considered to erode. 
Moreover, the proportion of individuals with Type A personality increased in younger female cohorts, followed by a decline in Type B personality. Both types approach similar proportions between females and males aged 30 to 49 . But the dynamic was mainly influenced by personality changes among females. In fact, those results reflect the conditions in the mid 1980s. According to the experiences of the physicians, the changes in gender role orientation continued which had effects on the overall health behaviour of men and women and the smoking prevalence in detail. A positive association between Type A personality and higher smoking prevalence could be found among females aged 40-49 in 1984/86. Especially, these women were the forerunners of the emancipation. In contrast, Type B personality was associated with smoking among men aged 50-59. Due to the higher smoking related mortality among men with type A personality for ages 50 and onwards, our sample may be selective and our unexpected results for Type B may be explained by this selectivity. Previous studies had analysed higher smoking rates among individuals with Type A personality (Blascovich, Major \& Katkin 1981; Shekelle, Schoenberger \& Stamler 1976). The risk of chronic diseases is higher among those earlyold individuals which could be caused higher rates of smoking cessation.

The overall influence of personality, however, reveals only a small association with smoking behaviour. Indeed, the quantitative effects are not contrary to the qualitative results because the quantitative measure covers only one part of the gender role concept. Moreover, workforce participation together with changes in traditional gender influenced smoking behaviour. High job demands are associated with higher amount of tobacco products being smoked (Albertsen, Borg \& Oldenburg 2006). Furthermore, our analyses indicate that for women smoking constitutes a coping strategy for stress resulting, among others, from multiple responsibilities due to the reconciliation of work and family life. These results are consistent with the outcome of Brunswick and Messeri (1984). Whereas the qualitative results provide reasons for higher smoking prevalence among employed women, the quantitative results confirm general differences between employed and nonemployed women aged 30 to 49. Indeed, the effect of pension at ages 60-69 on lower likelihood of being current smokers is similar among both women and men. This result leads to the assumption that workforce participation generally increases the risk of smoking. As mentioned above, the higher likelihood of smoking among employed women may be caused due to the stressful influence of multiple responsibilities. Beside, the higher likelihood of smoking among ever married women can be related to the negative influence of stress. Except for the last age group, especially divorced women who are particularly affected by both roles as paid worker and housewife contribute to the negative association with smoking.

Moreover our analysis supports another interesting hypothesis: not only women adopt a male lifestyle, also men adopt a female lifestyle which is positive especially for young men, because they do more for their body and inform themselves more often about health. Since the better health behaviour of women was regarded to be associated with their feminine attitudes the adoption of these attitudes by men shows a positive outcome for them. Women-on the contrary-adopt those negative behaviours of men which makes them act unhealthier nowadays compared to decades ago. This result is also supported by the hypothesis that the average man and woman show androgynous traits and therefore they are considered to react more equally concerning health behaviour. Since men are, 
nowadays, more open for health prevention and have a better access to their body and emotionality, consequently the media address these needs and in doing so promote health prevention checkups which in turn are positive for men's health behaviour.

It can be concluded that traditional gender roles have been changing which has effects on the overall health behaviour of men and women. Indeed, masculinity itself does slightly predict smoking behaviour among women and men. Moreover, the triangulation offers that changes in social conditions were related to continuous access to former male lifestyle and behaviour by females over time. Females adjusted femininity by traditional male risk behaviours. This result supports the gender roles modernization hypothesis (Waldron 2000). On the other hand, men increasingly adopt feminine lifestyles according to body sensitiveness and health check-ups. To sum up the changing health behaviour of men and women especially with regard to smoking may partly explain the narrowing of the gender gap in mortality because it is expected that former benefits of health for women diminish due to the adaptation of risky behaviour but become increasingly relevant to reducing mortality among men. 


\section{References}

Albertsen, K., Borg, V. \& Oldenburg, B. 2006, 'A systematic review of the impact of work environment on smoking cessation, relapse and amount smoked', Preventive Medicine, vol. 43, no. 4, pp. 291-305.

Ali, S.M., Chaix, B., Merlo, J., Rosvall, M., Wamala, S. \& Lindström, M. 2009, 'Gender differences in daily smoking prevalence in different age strata: A population-based study in southern Sweden', Scandinavian Journal of Public Health, vol. 37, pp. 146152.

Begley, C.M. 1996, 'Using triangulation in nursing research', Journal of Advanced Nursing, vol. 24, pp. 122-128.

Bem, S.L. 1974, 'The measurement of psychological androgyny', Journal of Consulting and Clinical Psychology, vol. 42, pp. 155-162.

Blascovich, J., Major, B. \& Katkin, E.S. 1981, 'Sex-role orientation and Type A behavior', Personality and Social Psychology Bullentin, vol. 7, no. 4, pp. 600-604.

Brunswick, A.F. \& Messeri, P.A. 1984, 'Gender differences in the processes leading to cigarette smoking', Journal of Consulting and Clinical Psychology, vol. 54, pp. 342-346.

Corbin, J. \& Strauss, A. 1990, 'Grounded theory research: procedures, canons, and evaluative criteria', Qualitative Sociology, vol. 13, no. 1, pp. 3-21.

Courtenay, W.H. 2000, 'Construction of masculinity and their influence on men's wellbeing: a theory of gender and health', Social Science and Medicine, vol. 50, pp. $1385-1401$.

Degregorio, E. \& Carver, C.S. 1980, 'Type A behavior pattern, sex role orientation, and psychological adjustment', Journal of Personality and Social Psychology, vol. 39, no. 2, pp. 286-293.

Denzin, N.K. 1989, The research act: A theoretical introduction to sociological methods, Prentice Hall, Englewood Cliffs, N.J.

Emslie, C., Hunt, K. \& Macintyre, S. 2002, 'How similar are the smoking and drinking habits of men and women in non-manual jobs?', European Journal of Public Health, vol. 12 , pp. 22-28.

Flick, U. 2006, An introduction to qualitative research, Sage Publications, London.

Garfield, C.F., Isacco, A. \& Rogers, T.E. 2008, 'A Review of Men's Health and Masculinity', American Journal of Lifestyle Medicine, vol. 2, no. 6, pp. 474-487. 
Gärtner, K. 2001, Lebensstile und ihr Einfluss auf Gesundheit und Lebenserwartung. Der Lebenserwartungssurvey des $\mathrm{BiB}$, Bundesinstitut für Bevölkerungsforschung, Wiesbaden.

Graham, H. 1996, 'Smoking prevalence among women in the European Community 19501990', Social Science and Medicine, vol. 43, no. 2, pp. 243-254.

Grunberg, N.E., Winders, S.E. \& Wewers, M.E. 1991, 'Gender Differences in Tobacco Use', Health Psychology, vol. 10, no. 2, pp. 143-153.

Harrison, J. 1978, 'Warning: The male sex role may be hazardous to your health', Journal of Social Issue, vol. 34, pp. 65-86.

Haustein, K.O. 2001, Tabakabhängigkeit. Gesundheitliche Schäden durch das Rauchen. Ursachen-Folgen-Behandlungsmöglichkeiten-Konsequenzen für Politik und Gesellschaft, Deutscher Ärzte-Verlag, Köln.

Haynes, S. \& Feinleib, M. 1980, 'Women, work and coronary disease: Prospective findings from the Framingham heart study', American Journal of Public Health, vol. 70, pp. 133-141.

Helmert, U., Borgers, D. \& Bamman, K. 2001, 'Soziale Determinanten des Rauchverhaltens in Deutschland: Ergebnisse des Mikrozensus 1995', Sozial- und Präventivmedizin, vol. 46, no. 3, pp. 172-181.

Hunt, K., Hannah, M.-K. \& West, P. 2004, 'Contextualizing smoking: masculinity, femininity and class differences in smoking in men and women from three generations in the west of Scotland', Health Education Research, vol. 19, no. 3, pp. 239-249.

Jenkins, C.D. 1976, 'Recent evidence supporting psychologic and social risk factors for coronary disease', The New England Journal of Medicine, vol. 294, pp. 1033-1038.

Jick, T.D. 1979, 'Mixing qualitative and quantitative methods: triangulation in action', Administrative Science QuarterlyQualitative Methodology, vol. 24, no. 4, pp. 602611.

Kuh, D. \& Ben-Shlomo, Y. (eds) 2004, A life course approach to chronic disease epidemiology, Oxford University Press, Oxford.

Lamnek, S. 1995, Qualitative Sozialforschung Band 2: Methoden und Techniken, Beltz, Weinheim.

Lopez, A.D., Collishaw, N.E. \& Piha, T. 1994, 'A descriptive model of the cigarette epidemic in developed countries', Tobacco Control, vol. 3, pp. 242-247. 
Lopez, A.D., Mathers, C.D., Ezzati, M., Jamison, D.T. \& Murray, C.J.L. 2006, Global burden of disease and risk factors, Oxford University Press \& World Bank, New York.

Luy, M., Wegner, C. \& Lutz, W. 2010, 'Adult mortality trends in Europe', in International Handbook of Adult Mortality, eds R.G. Rogers \& E.M. Crimmins, Springer: in press, Heidelberg et al.

Luy, M. \& Zielonke, N. 2009, 'Die geschlechtsspezifischen Sterblichkeitsunterschiede in West- und Ostdeutschland unter besonderer Berücksichtigung der kriegsbedingten Langzeitfolgen auf die Kohortenmortalität', in Die Bevölkerung in Ost- und Westdeutschland Demografische, gesellschaftliche und wirtschaftliche Entwicklungen seit der Wende, eds I. Cassens, M. Luy \& R. Scholz, VS Verlag für Sozialwissenschaften, Wiesbaden, pp. 169-198.

Mahalik, J.R., Burns, S.M. \& Syzdek, M. 2007, 'Masculinity and perceived normative health behaviors as predictors of men's health behaviors', Social Science and Medicine, vol. 64, pp. 2201-2209.

Meuser, M. \& Nagel, U. 1997, 'Das ExpertInneninterview. Wissenssoziologische Voraussetzungen und methodische Durchführung', in Handbuch Qualitative Forschungsmethoden in der Erziehungswissenschaft, eds B. Friebertshäuser \& A. Prengel, Juventa, Weinheim und Basel, pp. 481-491.

Oecd 1999, Classifying educational programmes.Manual for ISCED-97 implementation in OECD countries, Organisation for Economic,Co-operation and Development, Paris.

Pampel, F.C. 2001, 'Cigarette Diffusion and Sex Differences in Smoking', Journal of Health and Social Behavior, vol. 42, no. 4, pp. 388-404.

Pampel, F.C. 2002, 'Cigarette Use and the Narrowing Sex Differential in Mortality', Population and Development Review, vol. 28, no. 1, pp. 77-104.

Pierce, J.P. 1989, 'International Comparison of Trends in Cigarette Smoking Prevalence', American Journal of Public Health, vol. 79, no. 2, pp. 152-157.

Ramström, L.M. 1997, 'Prevalence and Other Dimensions of Smoking in the World', in The Tobacco EpidemicProg Respir Res, eds C.T. Bollinger \& K.O. Fagerström, Karger, Basel, pp. 64-77.

Shekelle, R.B., Schoenberger, J.A. \& Stamler, J. 1976, 'Correlates of the JAS type-A behavior pattern score', Journal of Chronic Disease, vol. 29, pp. 381-394.

Sieverding, M. 2005, 'Geschlecht und Gesundheit', in Gesundheitspsychologie (Enzyklopädie der Psychologie, Serie D), ed. R. Schwarzer, Hogrefe, Göttingen, pp. 55-70. 
Spence, J.T. \& Helmreich, R.L. 1978, Masculinity \& Femininity. Their psychological dimensions, correlates, and antecedents, University of Texas Press, Austin.

Stellman, S.D. \& Resnicow, K. 1997, 'Tobacco smoking, cancer and social class', Social Inequalities and Cancer, vol. 138, pp. 229-250.

Usdhhs 2001, Women and Smoking. A Report of the Surgeon General, National Center for Chronic Disease Prevention and Health Promotion, Office on Smoking and Health, Atlanta, Georgia.

Verband Deutscher Rentenversicherer 2009, Rentenversicherung in Zeitreihen, Berlin.

Wagenknecht, L.E., Perkins, L.L., Cutter, G.R., Sidney, S., Burke, G.L., Manolio, T.A., Jacobs, D.R., Liu, K., Friedman, G.D., Hughes, G.H. \& Hulley, S.B. 1990, 'Cigarette smoking behavior is strongly related to educational status: The CARDIA Study', Preventive Medicine, vol. 19, pp. 158-169.

Waldron, I. 1978, 'The coronary-prone behavior pattern, blood pressure, employment and socio-economic status in women', Journal of Psychosomatic Research, vol. 22, pp. 79-87.

Waldron, I. 1988, 'Gender and health-related behavior', in Health behavior: Emerging research perspectives, ed. D.S. Gochman, Springer, Berlin.

Waldron, I. 1991a, 'Effects of Labor Force Participation on Sex Differences in Mortality and Morbidity', in Women, Work, and Health, eds M. Frankenhaeuser, U. Lundberg \& M. Chesney, Plenum Press, New York \& London, pp. 17-38.

Waldron, I. 1991b, 'Pattern and causes of gender differences in smoking', Social Science and Medicine, vol. 32, no. 9, pp. 989-1005.

Waldron, I. 2000, 'Trends in gender differences in mortality: Relationships to changing gender differences in behaviour and other causal factors', in Gender inequalities in health, eds E. Annandale \& K. Hunt, Open University Press, Buckingham, pp. 150181. 


\section{VIENNA INSTITUTE OF DEMOGRAPHY}

\section{Working Papers}

Barakat, Bilal, Johannes Holler, Klaus Prettner, and Julia Schuster, The Impact of the Economic Crisis on Labour and Education in Europe, VID Working Paper 06/2010.

Grafeneder-Weissteiner, Theresa and Klaus Prettner, Agglomeration Processes in Ageing Societies, VID Working Paper 05/2010.

Buber, Isabella, Parity-specific weights for the Austrian Generations and Gender Survey, VID Working Paper 04/2010.

Testa, Maria Rita, She wants, he wants: Couple's childbearing desires in Austria, VID Working Paper 03/2010.

Buber, Isabella, Wissenschaftlerinnen in Österreich - Zusatzerhebung im Rahmen des GGS.Dokumentation der Datenerhebung und deskriptive Ergebnisse, VID Working Paper 02/2010.

Kuhn, Michael, Stefan Wrzaczek, Alexia Prskawetz, and Gustav Feichtinger, Externalities in a Life-Cycle Model with Endogenous Survival, VID Working Paper $01 / 2010$.

Prettner, Klaus, Population Ageing and Endogenous Economic Growth, VID Working Paper 08/2009.

Št’astná, Anna and Tomáš Sobotka, Changing Parental Leave and Shifts in Second and Third-Birth Rates in Austria, VID Working Paper 07/2009.

Prettner, Klaus and Alexia Prskawetz, Decreasing Fertility, Economic Growth and the Intergenerational Wage Gap, VID Working Paper 06/2009.

Wegner, Christian and Marc Luy, Determinants of General Health and Specific Diseases of Elderly Women and Men: A Longitudinal Analysis for Western and Eastern Germany, VID Working Paper 05/2009.

Wrzaczek, Stefan, Michael Kuhn, Alexia Prskawetz, and Gustav Feichtinger, The Reproductive Value in Distributed Optimal Control Models, VID Working Paper 04/2009.

The Vienna Institute of Demography Working Paper Series receives only limited review. Views or opinions expressed herein are entirely those of the authors. 